\title{
Surfactant era and obstetric decision making
}

\author{
Deeksha Pandey ${ }^{1}$, Supriya Sundar Mishra ${ }^{2}$, Rahul Raheja ${ }^{2}$, Abha Shrestha ${ }^{2}$, Aashish Saxena ${ }^{2}$, Leslie E Lewis ${ }^{3}$ \\ Sri Lanka Journal of Obstetrics and Gynaecology 2012; 34: 99-105
}

\begin{abstract}
Introduction: The management of women with pregnancy complications at the peri-viability period involves a complex set of medical, ethical, emotional, and social challenges for the obstetrician. The survival rate of preterm babies has been improving along with advancement in neonatal intensive care unit (NICU) technology. Our recent experience has shown survival of even very preterm infants with the use of surfactant therapy.
\end{abstract}

Objective: This observational study was conducted in order to evaluate the survival benefit of surfactant therapy on preterm neonates, to enable straight forward decisions to be taken by the obstetricians regarding antenatal steroid prophylaxis, in-utero transfer and mode of delivery in case of inevitable preterm births.

Material and Methods: This study was conducted in the NICU of a tertiary hospital over a period of 3 years (2009-2011). We recruited only those preterm neonates who received surfactant therapy and the records were obtained and analyzed. Survival benefits of surfactant therapy, role of antenatal steroids, in utero transfer and mode of delivery were studied.

Results: Almost all (98.6\%) neonates who did not receive antenatal steroids at all, landed up in respiratory distress syndrome (RDS) requiring surfactant therapy. Among the outborns $59.2 \%$ had an extended NICU stay as compared to $49.4 \%$ in the inborn group. The overall incidence of RDS was found to be more in caesarean delivery group (96.3\%). However if the period of gestation at the time of delivery

\footnotetext{
${ }^{1}$ Associate Professor, Department of Obstetrics and Gynaecology,

${ }^{3}$ Professor, Department of Paediatrics,

${ }^{2}$ Kasturba Medical College, Manipal

Manipal University, Manipal, Karnataka, India.

Correspondence: Deeksha Pandey

E-mail: deekshiiiobg@gmail.com
}

was less than 28 weeks, caesarean delivery had lesser incidence $(12.5 \%)$ of RDS compared to vaginal delivery $(27.1 \%)$. Similar finding was noted when comparing mortality. In less than 28 weeks gestation, when caesarean was done $2.5 \%$ newborn babies died, whereas in the vaginal delivery group $12.5 \%$ babies succumbed to death.

Conclusion: 1) Even in centers with facilities of surfactant therapy, steroids prophylaxis should be considered before delivery 2) Obstetricians should practice in utero transfer, to centers with NICU, having availability and technical expertise of surfactant prophylaxis 3) With the availability and wide spread usage of surfactant for premature neonates caesarean delivery should not be deferred for fetal benefit.

Key words: preterm, surfactant, neonatal intensive care unit (NICU), respiratory distress syndrome (RDS), period of gestation (POG)

\section{Introduction}

Management of women with pregnancy complications at gestations near the "border of viability" (periviability period) involves a complex set of medical, ethical, emotional, and social challenges for the obstetricians.

In second trimester with pregnancy complications, when expeditious delivery becomes mandatory, after weighing the risks and benefits, decision of terminating pregnancy, depends on the period of gestation (POG). After the age of viability and before 34 completed weeks, it is prudent to wait if possible up-to 24 hours after the second dose of antenatal steroids is administered and caesarean is the preferred mode of delivery, if cervix is not favorable. Prior to the age of viability, if need of pregnancy termination arises the decision is directed more towards maternal well being. Induction of labor (if not contraindicated) is the preferred modality of management. This kind of decision owes to the fact that the rates of death and various morbidities including respiratory distress syndrome (RDS) are distressingly high in this group of neonates. 


\section{Is the scenario changing?}

The survival rate of preterm babies has been improving along with advancements in development of newer generation mechanical ventilators, use of non-invasive ventilation and the wide spread use of surfactant $t^{1,2,3}$.

With all this in mind the peri-viability period, becomes a perplexing area for the obstetrician to take a clinically and ethically sound decision. There is no systematic documentation on the period of viability in India. Ten years ago in the developed countries, the minimum gestational age of viability was 28 weeks and on an average we are still following the same guideline.

Surfactant usage by the neonatologists in a standard neonatal intensive care unit (NICU) has expanded the grey area for the obstetricians. Our recent experience has shown survival of even very preterm infants with the use of surfactant therapy.

We hypothesize that there is a need to rethink while taking a decision regarding the pregnancy management in a very preterm pregnancy in terms of buying time for steroid prophylaxis, mode of delivery, in utero transfer to a centre having good NICU with availability and expertise of surfactant administration.

\section{Objective}

In a tertiary care center we conducted this observational study in order to evaluate the survival benefit of surfactant therapy on very preterm neonates, in order to help the obstetricians to take the following decisions:

1) Decision to terminate a very preterm pregnancy has been taken, is there a need of in-utero transfer to a centre having good NICU with facilities and expertise for surfactant administration?

2) Is there a role of buying time for steroid prophylaxis, in presence of facilities to provide surfactant therapy after birth?

3) With the availability of surfactant therapy is there a need to give a second thought to the mode of delivery (vaginal versus caesarean delivery) for the benefit of the fetus, in cases of very preterm pregnancies?

\section{Material and methods}

We analyzed the data of preterm infants admitted in the NICU of a tertiary hospital, over a period of 3 years (2009-2011). All neonates included in the study were below 34 weeks period of gestation and received surfactant therapy either as prophylaxis and/or rescue therapy. We included all these 128 neonates in our study. Surfactant therapy was administered either as prophylaxis or rescue. Prophylactic surfactant was given to those newborns who were either less than 28 weeks period of gestation or had birth weight of less than $1000 \mathrm{gm}$. It was given to those preterm neonates also who had respiratory distress and required ventilation at birth. Rescue surfactant therapy was administered for those neonates who required $\mathrm{FiO} 2$ of more than $40 \%$ on non-invasive ventilation (CPAP - continuous positive airway pressure) with respiratory distress score of 5 or more. Survival benefits of surfactant therapy, role of additional antenatal steroids, and adverse effects were studied.

\section{Results}

In last three years, we had 340 preterm neonates admitted in our NICU, out of which 128 had received surfactant therapy. Mean age of mothers of these neonates was 26.5 years $(95 \%$ confidence interval: 25.8-27.2), with $47.6 \%$ of mothers being in the age group of $25-30$ years. For more than half $(54.7 \%)$ of these mothers this was their first pregnancy. Around a third of these $(31.3 \%)$ neonates were delivered at 30 to 32 weeks POG. This was followed by neonates delivered at 28 to 30 weeks and 32 to 34 weeks $(24.2 \%$ and $21.1 \%$ respectively). Notably all these babies were the result of singleton pregnancy. Most common antenatal complication found in our study was pre eclampsia (defined as blood pressure of 140/90 $\mathrm{mmHg}$ or more with proteinuria after 20th week of period of gestation in a previously normotensive and non proteinuric woman- $35.2 \%$ ), followed by preterm pre-labor rupture of membranes (PPROM: spontaneous rupture of membranes, anytime beyond 28th week but before 37 th completed weeks of pregnancy and before the onset of labor- $21.1 \%$ ), intrauterine growth restriction (IUGR- taken as estimated fetal weight below 10th percentile of the average for the gestational age) and antepartum hemorrhage (APH- bleeding from or into the genital tract after the 28th week of pregnancy either due to placenta previa or abruption), gestational diabetes mellitus (GDM- glucose intolerance of variable severity with onset or first identified during the present pregnancy-9.4\%) and polyhydramnios (amniotic fluid index (AFI) $25 \mathrm{~cm}$ or more $3.1 \%$ ) (Table 1).

In the study group as a whole we met with a total mortality of 21 neonates $(16.4 \%)$. RDS occurred in $93.8 \%$ of neonates. Other morbidities were due to intraventricular hemorrhage (IVH-defined as is bleeding inside or around the ventricles, the spaces in the brain containing the cerebral spinal fluid) 11 (8.6\%), necrotizing enterocolitis (NEC- is a medical condition where portions of the bowel undergo necrosis (tissue death) $3(2.3 \%)$ and retinopathy of prematurity (ROPis a disease that affects immature vasculature in the eyes of premature babies) 21 (16.4\%). 
A quarter of pregnant women $(26.6 \%)$ had received full dose of antenatal steroid prophylaxis (either betamethasone or dexamethasone), while 18.8\% could receive incomplete dose (single injection) of prophylactic steroids before they delivered. More than half $(54.7 \%)$ women had not received even a single steroid injection before delivery (no steroid prophylaxis group) (Table 2). Almost all (98.6\%) neonates who did not receive antenatal steroids at all landed up with RDS requiring surfactant therapy. Even with incomplete dose of antenatal steroids $87.5 \%$ of babies developed RDS as compared to $82.4 \%$ who had received the complete dose. Interesting fact to be noted is 6 of those babies who delivered after 34 weeks developed RDS. All of these belonged to the group where antenatal steroid prophylaxis was not administered. It is evident in Table 2 that giving incomplete course of antenatal steroids was as good as giving no steroids, in term of mortality, major morbidities and extended NICU stay.
In order to evaluate the role of in utero transfer of preterm babies to a center with facilities of NICU care, we analyzed the outcome of babies who delivered with us compared to those who were delivered outside and brought directly to NICU (Table 3). We found that 49 $(38.3 \%)$ neonates were born outside and then brought to our Institution for NICU care. Incidence of RDS was found to be higher in babies who were outborn $(97.9 \%$ versus $91.9 \%$ ). Among the outborns $59.2 \%$ had an extended NICU stay as compared to $49.4 \%$ in the inborn group. Major morbidities like IVH, NEC and ROP was comparable between the two groups. The point to be appreciated is that mortality though seems to be higher in babies who were either booked with us or were transferred in utero, had an overall survival advantage of higher POG and birth weight. The mean POG of the outborn babies as well as the birth weight (mean POG 31.5 \pm 2.4 weeks; mean birth weight 1567.4 $\pm 518.6 \mathrm{gms}$ ) was better as compared to that of inborn babies (mean POG $30.3 \pm 2.6$ weeks; mean birth weight $1361.8 \pm 535.2 \mathrm{gms})$.

Table 1. Demographic characteristics of the studied population $(n=128)$

\begin{tabular}{|c|c|c|}
\hline $\begin{array}{l}\text { Variables } \\
\text { Maternal demographic data } \\
\text { Mean Age (95\% CI) } 26.5 \text { (25.8 to 27.2) }\end{array}$ & Absolute numbers (n) & Percentage \\
\hline$<20$ years & 04 & $03.1 \%$ \\
\hline $20-24$ years & 36 & $28.1 \%$ \\
\hline $25-29$ years & 60 & $46.9 \%$ \\
\hline $30-34$ years & 24 & $18.8 \%$ \\
\hline 35 years and above & 04 & $03.1 \%$ \\
\hline \multicolumn{3}{|l|}{ Parity } \\
\hline Primiparous & 70 & $54.7 \%$ \\
\hline \multicolumn{3}{|c|}{ Period of gestation (POG) at delivery (in weeks) } \\
\hline Less than 28 & 23 & $18.0 \%$ \\
\hline $28+1$ to 30 & 31 & $24.2 \%$ \\
\hline $30+1$ to 32 & 40 & $31.3 \%$ \\
\hline $32+1$ to 34 & 27 & $21.1 \%$ \\
\hline $34+1$ and more & 07 & $05.5 \%$ \\
\hline \multicolumn{3}{|l|}{ Pregnancy complications } \\
\hline PPROM & 27 & $21.1 \%$ \\
\hline GDM & 12 & $09.4 \%$ \\
\hline Pre eclampsia & 45 & $35.2 \%$ \\
\hline IUGR & 17 & $13.3 \%$ \\
\hline Polyhydramnios & 04 & $03.1 \%$ \\
\hline $\mathrm{APH}$ & 14 & $10.9 \%$ \\
\hline
\end{tabular}

PPROM - Prelabor preterm rupture of membranes, GDM - gestational diabetes mellitus, IUGR - intra uterine growth restriction, APH - antepartum hemorrhage. 
Table 2. Effect of antenatal corticosteroids on neonatal outcome

\begin{tabular}{|c|c|c|c|}
\hline Neonatal outcome & $\begin{array}{l}\text { No steroid prophylaxis } \\
\qquad(n=70)\end{array}$ & $\begin{array}{c}\text { Incomplete dose } \\
(n=24)\end{array}$ & $\begin{array}{l}\text { Complete dose } \\
\qquad(\mathrm{n}=34)\end{array}$ \\
\hline Respiratory distress Syndrome (RDS) & $69(98.6 \%)$ & $21(87.5 \%)$ & $28(82.4 \%)$ \\
\hline Less than $28(n=23)$ & 11 & 05 & 07 \\
\hline $28+1$ to $30(n=31)$ & 08 & 10 & 12 \\
\hline $30+1$ to $32(n=40)$ & 26 & 03 & 08 \\
\hline $32+1$ to $34(n=27)$ & 18 & 03 & 02 \\
\hline More than $34(\mathrm{n}=07)$ & 06 & 00 & 01 \\
\hline Morbidity (NEC + IVH+ROP) & $15(21.4 \%)$ & $7(29.2 \%)$ & $8(23.5 \%)$ \\
\hline Less than $28(n=23)$ & 03 & 03 & 03 \\
\hline $28+1$ to $30(n=31)$ & 03 & 02 & 02 \\
\hline $30+1$ to $32(n=40)$ & 05 & 02 & 03 \\
\hline $32+1$ to $34(n=27)$ & 04 & 00 & 00 \\
\hline Extended NICU stay (>15 days) & $42(60 \%)$ & $09(37.5 \%)$ & 17 (50\%) \\
\hline Less than 28 & 07 & 02 & 04 \\
\hline $28+1$ to 30 & 06 & 03 & 08 \\
\hline $30+1$ to 32 & 16 & 03 & 04 \\
\hline $32+1$ to 34 & 11 & 01 & 01 \\
\hline More than 34 & 02 & 00 & 00 \\
\hline Mortality & $11(15.7 \%)$ & $05(20.8 \%)$ & $05(14.7 \%)$ \\
\hline Less than 28 & 06 & 01 & 01 \\
\hline $28+1$ to 30 & 01 & 04 & 04 \\
\hline $30+1$ to 32 & 03 & 00 & 00 \\
\hline $32+1$ to 34 & 00 & 00 & 00 \\
\hline More than 34 & 01 & 00 & 00 \\
\hline
\end{tabular}

RDS - Respiratory distress syndrome, NICU - neonatal intensive care unit, NEC - necrotizing enterocolitis, IVH - intra-ventricular hemorrhage, ROP - retinopathy of prematurity.

Table 3. Role of inutero transfer in preventing complications/improving outcome

\begin{tabular}{lcc}
\hline Neonatal outcome & Inborn $(n=79)$ & Outborn $(n=49)$ \\
Mean POG in wks $(95 \% \mathrm{CI})$ & $30.3(29.8$ to 30.9$)$ & $31.5(30.8$ to 32.2$)$ \\
Mean Birth weight in gms $(95 \% \mathrm{CI})$ & $1361.8(1241.9$ to 1481.7$)$ & $1567.4(1418.4$ to 1716.3$)$ \\
\hline Respiratory distress syndrome (RDS) & $72(91.1 \%)$ & $48(97.9 \%)$ \\
Less than $28(\mathrm{n}=23)$ & 17 & 06 \\
$28+1$ to $30(\mathrm{n}=31)$ & 24 & 20 \\
$30+1$ to $32(\mathrm{n}=40)$ & 17 & 12 \\
$32+1$ to $34(\mathrm{n}=27)$ & 11 & 04 \\
More than $34(\mathrm{n}=07)$ & 03 & $11(22.4 \%)$ \\
Morbidity $(\mathrm{NEC}+\mathbf{I V H + R O P})$ & $18(22.8 \%)$ & 3 \\
Less than $28(\mathrm{n}=23)$ & 6 & 2 \\
$28+1$ to $30(\mathrm{n}=31)$ & 5 & 6 \\
$30+1$ to $32(\mathrm{n}=40)$ & 4 & 0 \\
$32+1$ to $34(\mathrm{n}=27)$ & 3 & (Continued)
\end{tabular}




\begin{tabular}{|c|c|c|}
\hline $\begin{array}{l}\text { Neonatal outcome } \\
\text { Mean POG in wks (95\% CI) } \\
\text { Mean Birth weightin gms }(95 \% \text { CI) }\end{array}$ & $\begin{array}{c}\text { Inborn }(n=79) \\
30.3(29.8 \text { to } 30.9) \\
1361.8(1241.9 \text { to } 1481.7)\end{array}$ & $\begin{array}{c}\text { Outborn }(n=49) \\
31.5(30.8 \text { to } 32.2) \\
1567.4(1418.4 \text { to } 1716.3)\end{array}$ \\
\hline Extended NICU stay (>15 days) & $39(49.4 \%)$ & $29(59.2 \%)$ \\
\hline Less than 28 & 09 & 04 \\
\hline $28+1$ to 30 & 13 & 04 \\
\hline $30+1$ to 32 & 10 & 13 \\
\hline $32+1$ to 34 & 06 & 07 \\
\hline More than $34(n=07)$ & 1 & 1 \\
\hline Mortality & $14(17.7 \%)$ & $07(14.3 \%)$ \\
\hline Less than 28 & 6 & 2 \\
\hline $28+1$ to 30 & 8 & 1 \\
\hline $30+1$ to 32 & 0 & 3 \\
\hline $32+1$ to 34 & 0 & 0 \\
\hline More than $34(n=07)$ & 0 & 1 \\
\hline
\end{tabular}

RDS - respiratory distress syndrome, NICU - neonatal intensive care unit, NEC - necrotizing enterocolitis, IVH - intra-ventricular hemorrhage, ROP - retinopathy of prematurity.

Table 4. Role of mode of delivery in preventing complications/improving outcome

\begin{tabular}{|c|c|c|}
\hline Neonatal outcome & Vaginal delivery $(n=48)$ & Cesarean delivery $(n=80)$ \\
\hline Mean POG $(95 \%$ CI) & $30.0(29.2$ to 30.9$)$ & 31.3 (30.7 to 31.8) \\
\hline Mean birth weight (95\% CI) & 1434.7 (1263.8 to 1605.7$)$ & $1444.0(1331.3$ to 1556.6$)$ \\
\hline Respiratory distress syndrome (RDS) & $43(89.6 \%)$ & $77(96.3 \%)$ \\
\hline Less than $28(n=23)$ & 13 & 10 \\
\hline $28+1$ to $30(n=31)$ & 12 & 18 \\
\hline $30+1$ to $32(n=40)$ & 12 & 27 \\
\hline $32+1$ to $34(n=27)$ & 03 & 20 \\
\hline More than $34(n=07)$ & 03 & 04 \\
\hline Morbidity (NEC+IVH+ROP) & $12(25 \%)$ & $18(22.5 \%)$ \\
\hline Less than 28 & 03 & 06 \\
\hline $28+1$ to 30 & 02 & 05 \\
\hline $30+1$ to 32 & 07 & 03 \\
\hline $32+1$ to 34 & 00 & 04 \\
\hline Extended NICU stay (>15 days) & $22(45.8 \%)$ & $46(57.5 \%)$ \\
\hline Less than 28 & 06 & 07 \\
\hline $28+1$ to 30 & 05 & 12 \\
\hline $30+1$ to 32 & 09 & 14 \\
\hline $32+1$ to 34 & 01 & 12 \\
\hline More than 34 & 01 & 0 \\
\hline Mortality & $8(16.7 \%)$ & $13(16.3 \%)$ \\
\hline Less than 28 & 06 & 02 \\
\hline $28+1$ to 30 & 02 & 07 \\
\hline $30+1$ to 32 & 00 & 03 \\
\hline $32+1$ to 34 & 00 & 00 \\
\hline More than 34 & 00 & 01 \\
\hline
\end{tabular}

RDS - respiratory distress syndrome, NICU - neonatal intensive care unit, NEC - necrotizing enterocolitis, IVH - intra-ventricular hemorrhage, ROP - retinopathy of prematurity. 
Next we tried to compare the outcome of different modes of delivery (i.e., vaginal delivery versus caesarean delivery). The overall incidence of RDS was found to be more in caesarean delivery group (96.3\%) as compared to vaginal delivery group (89.6\%). However if the period of gestation at the time of delivery was less than 28 weeks, caesarean delivery had $12.5 \%$ incidence of RDS compared to vaginal delivery which was more than double of this $(27.1 \%)$. Similar finding was noted when comparing mortality. In less than 28 weeks gestation, when caesarean was done 2 out of $80(2.5 \%)$ newborn babies died, whereas in the vaginal delivery group 6 out of $48(12.5 \%)$ babies succumbed to death. The reason for a poor outcome in the caesarean group can be because of the fact that most of the caesareans in preterm are emergency caesareans and so already many of the babies in this group were compromised. However comparing neonatal outcome based on the indication of caesarean was out of the scope of present study.

\section{Discussion}

Use of surfactant has definitely revolutionized the prognosis of even very preterm babies. Our study shows that still obstetrician has a great role in improving survival and decreasing morbidity of these neonates. We emphasize here the role of antenatal steroids (full dose even after 34 weeks of gestation), in utero transfer and caesarean delivery for babies less than 28 weeks, to optimize the outcome where preterm delivery is imminent.

In 1959, for the first time, Avery and Mead ${ }^{4}$ reported that the deficiency of surface-active material in the lungs of preterm babies is the cause of RDS. This led to a chain reaction of clinical trials on artificial surface-active materials in neonates with RDS,6.6.

According to Society of Obstetricians and Gynaecologists of Canada (SOGC) guidelines, expectant mothers with threatened preterm labor should be given a course of steroid prophylaxis even with the availability of surfactant therapy ${ }^{7}$. Large cohort studies indicate that the combination of surfactant and steroids is more effective than exogenous surfactant alone $^{8}$. Two independent randomized controlled trials ${ }^{9,10}$ have confirmed that antenatal steroids continue to reduce the risk of poor outcome, even in centers where surfactant is available. Notably in our study group 6 babies who delivered after 34 weeks and were not given steroid prophylaxis developed RDS. This observation makes us rethink about the usual policy to administer steroids upto 34 weeks period of gestation only. Similar concept has also been advocated that antenatal steroid administration might be beneficial even after 34 weeks, in selected cases ${ }^{11,12,13}$.
When the question of prophylactic versus rescue surfactant therapy arises the recommendation is for infants at significant risk of RDS should receive prophylactic surfactant as soon as they are stable within a few minutes after intubation ${ }^{14}$. Surfactant replacement therapy should not be administered by anyone, anywhere rather it should be directed by physicians qualified and trained in its use and administration ${ }^{15}$. Keeping these factors in mind the obstetricians should practice in utero transfer, to centers with NICU with availability and technical expertise of surfactant prophylaxis, when the need to deliver a very preterm fetus arises.

Short-term risks of surfactant replacement therapy have been reported including bradycardia and hypoxemia during instillation, as well as blockage of the endotracheal tube ${ }^{16}$ and pulmonary hemorrhage following surfactant treatment; however, and overall mortality is definitely lower after surfactant therapy ${ }^{17}$.

\section{Conclusion}

1) Even in centers with facilities of surfactant therapy, steroids prophylaxis should be considered before a preterm delivery. Administration of antenatal steroids beyond 34 weeks should be considered in selected cases.

2) Obstetricians should practice in utero transfer, to centers with NICU having availability and technical expertise of surfactant prophylaxis, when the need to deliver a very preterm fetus arises.

3) With the availability and wide spread usage of surfactant for premature neonates caesarean delivery should not be deferred for fetal benefit.

\section{References}

1. Halliday HL. Surfactants: past, present and future. J Perinatol 2008; 28 Suppl 1: S47-56.

2. Dani C, Barp J, Berti E, Bertini G. Surfactant in the preterm infant: what's going on. J Matern Fetal Neonatal Med 2009; 22 Suppl 3: 3-5.

3. Jobe AH. Lung maturation: the survival miracle of very low birth weight infants. Pediatr Neonatol 2010; 51(1): 7-13.

4. Avery ME, Mead J. Surface properties in relation to atelectasis and hyaline membrane disease. Am J Dis Child 1959; 97: 517-23.

5. Robillard E, Alarie Y, Dagenais-Perusse P, Baril E, Guilbeault A. Microaerosol administration of synthetic dipalmitoyl lecithin in the respiratory distress syndrome: A preliminary report. CMAJ 1964; 90: 55-7.

6. Chu J, Clements JA, Cotton EK, et al. Neonatal pulmonary ischemia: Clinical and physiologic studies. Pediatrics 1967; 40(Suppl): 709-82. 
7. Crane J, Armson A, Brunner M, et al, for the Executive Committee of the Society of Obstetricians and Gynaecologists of Canada. Antenatal corticosteroid therapy for fetal maturation. J Obstet Gynaecol Can 2003; 25: 45-52.

8. Chien LY, Ohlsson A, Seshia MM, Boulton J, Sankaran K, Lee SK, for the Canadian Neonatal Network. Variations in antenatal corticosteroid therapy: A persistent problem despite 30 years of evidence. Obstet Gynecol 2002; 99: 401-8.

9. Kari MA, Hallman M, Eronen M, et al. Prenatal dexamethasone treatment in conjunction with rescue therapy of human surfactant: A randomized placebocontrolled multicenter study. Pediatr 1994; 93: 730-6.

10. Silver RK, Vyskocil C, Solomon SL, Ragin A, Neerhof MG, Farrell EE. Randomized trial of antenatal dexamethasone in surfactant-treated infants delivered before 30 weeks' gestation. Obstet Gynecol 1996; 87: 683-91.

11. Kamath-Rayne BD, DeFranco EA, Marcotte MP. Antenatal steroids for treatment of fetal lung immaturity after 34 weeks of gestation: an evaluation of neonatal outcomes. Obstet Gynecol 2012; 119(5): 909-16.

12. Surbek D, Drack G, Irion O, Nelle M, Huang D, Hoesli I. Antenatal corticosteroids for fetal lung maturation in threatened preterm delivery: indications and administration. Arch Gynecol Obstet 2012; 286(2): 277-81. Epub 2012 Apr 29.

13. Yinon Y, Haas J, Mazaki-Tovi S, Lapidot N, Mazkereth R, Hourvitz A, Sivan E, Schiff E, Weisz B. Should patients with documented fetal lung immaturity after 34 weeks of gestation be treated with steroids? Am J Obstet Gynecol 2012 Jun 29.

14. Recommendations for neonatal surfactant therapy. Canadian Paediatric Society (CPS). Paediatrics and Child Health 2005; 10(2): 109-16.

15. James A. Lemons, Lillian R. Blackmon, William P. Kanto, Jr, Hugh M. MacDonald. Surfactant Replacement Therapy for Respiratory Distress Syndrome. American Academy of Pediatrics Policy Statement 1999; 103: 684-5.

16. Hentschel R, Jorch G. Acute side effects of surfactant treatment. J Perinat Med 2002; 30: 143-8.

17. Long W, Corbet A, Cotton R, et al. A controlled trial of synthetic surfactant in infants weighing $1250 \mathrm{~g}$ or more with respiratory distress syndrome. The American Exosurf Neonatal Study Group I, and the Canadian Exosurf Neonatal Study Group. N Engl J Med 1991; 325: 1696-703. 